\title{
Brexit Referendum and the UK Securitization Market
}

\author{
Alper Kara*, Nodirbek Karimov and Anh Phuong Nguyen
}

\begin{abstract}
We examined the perceived risk of Brexit Referendum (BR) in the United Kingdom (UK) securitization market, using 1,021 securitized bonds issued between 2011 and 2018. We find an unexpected negative relationship between the BR outcome and the initial yield spreads of asset-backed securities (ABS), even after accounting for the downward-adjusted credit ratings in the post-BR period. We do not observe this effect for mortgage-backed securities (MBS). Our findings imply that investors diversified into ABS bonds under uncertainty in the post-BR period.
\end{abstract}

Keywords: Securitization; Brexit Referendum; United Kingdom; ABS/MBS Pricing

JEL Classification: G21; G28

\section{Introduction}

The announcement of the UK's vote to leave the European Union (EU) (i.e. "Brexit") is considered as one of the most significant economic events of the $21^{*}$ century. Brexit is expected to jeopardize the UK's economic stability and have potential long-term consequences. Various uncertainties exist around the eventual Brexit outcome. First, the direction that the UK will take following Brexit, in terms of regulation, fiscal policy and investment decisions is ambiguous. Second, Brexit may break the strong trading and financial system interconnectedness between the UK and the EU. The UK may lose its free trade access to the EU market. Third, UK banking sector may shrink substantially due to many banks moving headquarters to the EU. Literature has investigated the impact of Brexit referendum (BR) on financial markets (see among others Oehler et al., 2017; Aristeidis \& Elias, 2018; Arshad et al., 2019). They find that BR outcome produced a shock to the UK financial markets in the short-term. However, the impact had a limited effect in the medium- and long-term. The immediate spillover of the volatility were also observed in other markets (Aristeidis \& Elias, 2018; Li, 2019) and it is found that more severe stock market responses are concentrated amongst countries with higher debt to GDP ratios (Burdekin et al., 2017).

We investigate the impact of BR result on the UK securitization market. We examine how the pricing of asset-backed securities (ABS) and mortgage-backed securities (MBS) changed after the BR, using 1,021 bonds issued between 2011 and 2018. Our contribution to the literature is twofold. Firstly, this paper is the first to examine the impact of $\mathrm{BR}$ result on the securitization market. This is important as the structure, risk and return features of ABS/MBS bonds are different to corporate or sovereign bonds. ABS/MBS stand out by their unique structure of various assets being pooled together into marketable securities and provide opportunities for investors to diversify their portfolios to an extensive array of alternative assets to meet desired risk. Second, we contribute to the wider literature by providing recent empirical evidence on how uncertain political events impact markets through perceptions of investors. Understanding the possible impact of the BR on the UK securitization market is also important as it constitutes more than $50 \%$ of the total EU market volume (Deku \& Kara, 2017).

\footnotetext{
* Corresponding author: Alper Kara, e-mail: a.kara@hud.ac.uk, Tel: +4401484473084; Nodirbek Karimov, e-mail: Nodirbek.karimov@hud.ac.uk; Anh Phuong Nguyen anhphuong30593@gmail.com. All authors are affiliated with the University of Huddersfield, Business School, Queensgate, Huddersfield, HD1 3DH, UK
} 
Three theories explain markets' reaction to uncertain political events, which are expected to increase risk premium of a country (Pastor and Veronesi, 2012). The Uncertain Information Hypothesis (UIH) argues that for negative events the systematic risk of securities increases momentarily after large price changes causing rational, risk averse investors to demand a higher return for the increased risk (Brown et al., 1988). The UIH predicts that after adjusting for the risk component of the new information, the abnormal return of securities will be zero. Overreaction hypothesis posits that investors overreact to extreme and unexpected situations (Park, 1995), as they have tendency to overweight current information (DeBondt \& Thaler, 1985). In contrast, underreaction hypothesis argues that the new information is gradually incorporated into prices. In both cases prices are expected to revert to their risk adjusted values in the medium-term.

\section{Methodology and Data}

We model ABS/MBS bond $i$ to explain the primary yield spread as follows (Deku et al., 2019):

$$
\begin{aligned}
\text { Spread }_{i}= & \beta_{0}+\beta_{1} \text { Brexit }_{i}+\beta_{2} \text { Size }_{i}+\beta_{3} \text { Weighted average life }_{i}+\beta_{4} \text { CRA }_{i} \\
& +\beta_{5} \text { Private placement }_{i}+\beta_{6} \text { Mortgage }_{i} \\
& +\beta_{7} \text { Credit rating }_{i}+\beta_{8} \text { Issuer identity }_{i}+\beta_{9} \text { Time }_{i}+e_{i}
\end{aligned}
$$

where, Spread is the initial yield spread in basis points (bp) over the relevant benchmark rate. Brexit is 1 for the period after the referendum date (24/06/2016), 0 otherwise. Credit Rating is a set of dummy variables (from AAA to CCC-). Size is the amount of the issue. Weighted Average Life is the duration of the bond and captures the interest rate risk exposure. Credit Rating Agencies (CRA) is the number of reported ratings by the rating agencies for the bond. Mortgage is 1 if the bond is an MBS, 0 otherwise. Private placement is 1 if the bond is sold privately, 0 otherwise. We control for Issuer identity and time (quarterly).

We collect instrument level data from Bloomberg. We present descriptive analysis in Table 1. In Panel B we compare issues before and after the BR. We find that the mean spread remains at the same level (not statistically different), which provides evidence that the investor's risk perception, on average, has not changed after the BR. However, the average size and maturity of deals have decreased significantly post-BR. The mean credit rating has also increased substantially from 5.26 to $6.36^{1}$, which shows that ratings agencies adjusted ratings downwards for the risk of uncertainty due to Brexit. Panel C presents the distribution of ratings for the pre- and post- BR. There is a visible shift downwards in the ratings in the post-BR period. The UIH and empirical evidence suggest that yields of securities should normally increase to compensate for the escalation of risk after a political announcement (Smales, 2015). Surprisingly, for the post-BR period, we do not observe an increase. We observe that the ratings have decreased, which, ceteris paribus, should have been observed as an increase in the spreads. However, it seems that this effect is compensated by other factors, which we investigate further below.

\section{Results}

Regression results are presented in Table 2. Models are estimated with and without time controls. We find that Brexit is negative and significant, indicating that ABS/MBS bonds issued post-BR are priced 189 bps lower (Column 1). This finding is contradictory to the literature arguing that an unexpected political event should decrease the security prices due to additional risk (Pastor and Veronesi, 2012; Boutchkova et al., 2012). It is worth

\footnotetext{
${ }^{1}$ We map credit ratings onto a numerical scale where $\mathrm{AAA}=1, \mathrm{AA}+=2$ and $\mathrm{AA}=3$ and so on, based on a standardized 19 points whereby from $\mathrm{AAA}(1)$ to CCC- (19).
} 
noting that the decrease in prices is observed after controlling for the downward credit rating adjustments. Our results seem to be closer to the underreaction hypothesis.

We offer two possible explanations. First, ABS/MBS prices were pressured downwards as investors were shifting from equity to bond markets to mitigate potential risk. Investors become risk averse after unexpected political events by reducing exposure to equities and switching to fixed income securities (Connolly et al., 2005). There is evidence for this argument in the case of Brexit uncertainty (Schiereck et al. 2016, Akinsomi et al., 2018). In the post-BR period, economic and political uncertainty increased in the UK financial markets, which reduced demand for equities, and investors switched to fixed income securities, considered to be safer, in particular to government bonds (Schiereck et al., 2016). Within the bond market, securitized bonds provide an alternative to diversify with higher expected returns in comparison to government bonds. A full switch to government bonds may have been seen as unnecessary by investors, and securitized bonds may have provided an alternative to reduce risk by maintaining a higher portfolio return at the same time. Second, investors did not believe in the prospect of the UK leaving the EU. Investors' expectations could have been towards a softer Brexit where the impact on the UK economy would not be as dramatic as it was reflected by the rating downgrades. In other words, ABS/MBS prices did not fully reflect the uncertainty and risk that may be caused by the full implementation of BR result. This interpretation is supported by Aristeidis \& Elias' (2018) findings showing that the initial stock markets' response to BR result was short lived, perhaps due to the softer or "no Brexit" expectation. Similarly, our results indicate that investors' expectations may be geared towards a positive scenario.

Subsequently, we test whether the impact of BR on spreads differed depending on the level of risk taken. We hypothesise that if investors have shifted their funds to ABS/MBS for diversification, or believed that it would be a softer Brexit, then we should observe a larger negative BR impact on spreads for less risky securitizations. To test this hypothesis, we split the sample into two according to risk categories - prime (AAA) and non-prime (nonAAA). Results are presented in Table 3. We find that the Brexit is negative and significant for both types. However, its magnitude is larger for prime bonds. These results are consistent with both of our interpretations of as to why a negative effect is observed. If investors diversified away from equities to bond markets, and particularly to securitised bonds that have higher return prospects than government bonds, then it would be more plausible that they were cautious and invested in higher quality (i.e. less risky) ABS/MBS bonds. Hence, we observe a higher impact in AAA-rated bonds. If, on the other hand, investors expected a softer Brexit but still wanted to cautiously decrease their risk exposure due to uncertainty, then it is reasonable to argue that they preferred more of the prime bonds.

We also examine whether the same relationship is observed for MBS and ABS separately. MBS can be considered riskier as assets backing the bonds are less diversified, constituting only real estate assets. In contrast, ABS is diversified with various assets such as corporate loans, auto loans, leasing, and credit cards. We re-run the estimations separately for sub-groups. Results are reported in Table 4. We find that Brexit is negative and strongly significant for the ABS, but not for the MBS sample. Our main findings for the full sample seem to be driven by the ABS sample. A plausible explanation for this finding is that investors may have deemed ABS to be less risky because they are more diversified in comparison to MBS, which are much more vulnerable to volatility in the housing market. After all, UK real estate market is deemed to be more sensitive to political and economic uncertainties than other developed countries (Akinsomi et al., 2018). Our findings also indicate that investors may 
have considered the drop in the ratings of MBS bonds as satisfactory in capturing the potential risks of Brexit uncertainty, particularly due to the vulnerability of the real estate market. These findings support our main argument that investors have diversified into ABS bonds post-BR. We employ PSM for robustness checks. Results, presented in Table 5, are consistent with the regression findings.

\section{Conclusion}

We examined the perceived risk of BR in the UK securitization market. We find a negative relationship between

BR outcome and the initial yield spreads of ABS bonds, even after accounting for the downward-adjusted credit ratings in the post-BR period. We do not observe this effect for MBS bonds. Our findings imply that ABS bonds are considered as a diversification tool by investors under uncertainty in the post-BR period.

\section{References}

Akinsomi,O.,Coskun,Y.,Gupta,R.,\&Lau,C.K.M.(2018).Impact of volatility and equity market uncertainty on herd behaviour: evidence from UK REITs, Journal of European Real Estate Research,11(2),169-186.

Aristeidis,S., \&Elias, K.(2018).Empirical analysis of market reactions to the UK's referendum results-How strong will Brexit be? Journal of International Financial Markets, Institutions and Money,53,263-286.

Arshad,S.,Rizvi,S.A.R., \&Haroon,O.(2019).Impact of Brexit Vote on The London Stock Exchange: A Sectorial Analysis of Its Volatility And Efficiency. Finance Research Letters,fortcoming.

Burdekin,R.,Hughson,E.\&Gu,J.(2017).A first look at Brexit and global equity markets,Applied Economics Letters,25,136-140.

Boutchkova,M.,Doshi,H.,Durnev,A.,\&Molchanov,A.(2012).Precarious politics and return volatility.Review of Financial Studies, 25(4),1111-1154.

Connolly,R.,Stivers,C.,\&Sun,L.(2005).Stock market uncertainty and the stock-bond return relation,Journal of Financial and Quantitative Analysis, 4O(1),161-194.

De Bondt,W.F.,\&Thaler,R.(1985).Does the stock market overreact?Journal of Finance,40,793-805.

Deku,S.Y.,\&Kara,A.(2017).Securitization:Past, Present and Future.Springer International Publishing.

Deku,S.Y.,Kara,A.,\&Marques-Ibanez,D.(2019).Trustee reputation in securitization:When does it matter? Financial Markets, Institutions \& Instruments,28(2),61-84.

Li,H.(2019).Volatility spillovers across European stock markets under the uncertainty of Brexit.Economic Modelling,fortcoming.

Oehler,A.,Horn,M.,\&Wendt,S.(2017).Brexit:Short-term stock price effects and the impact of firm-level internationalization. Finance Research Letters, 22,175-181.

Park,J.(1995).A market microstructure explanation for predictable variations in stock returns following large price changes, Journal of Financial and Quantitative Analysis,30,241-256

Pastor,L.,\&Veronesi,P.(2012).Uncertainty about government policy and stock prices.Journal of Finance, 67(4),1219-1264.

Schiereck,D.,Kiesel,F.,\&Kolaric,S.(2016).Brexit:(Not) another Lehman moment for banks? Finance Research Letters, 19,291-297.

Smales,L.A.(2017)."Brexit”:A Case Study in the Relationship Between Political and Financial Market Uncertainty.International Review of Finance, 17(3),451-459. 
Table 1 Descriptive statistics

Panel A: All sample

\begin{tabular}{lccccc}
\hline Variable & Mean & Median & Std. Dev & Min & Max \\
\hline Spread (bps) & 263.00 & 215.00 & 178.84 & 13.00 & 1,025 \\
Brexit & 0.37 & 0.0 .00 & 0.48 & 0.00 & 1.00 \\
Size (million) & 4.14 & 3.68 & 1.46 & 0.32 & 8.73 \\
Weighted average life (years) & 35.00 & 30.40 & 31.40 & 0.60 & 100.00 \\
Credit rating & 5.71 & 3.00 & 4.64 & 1.00 & 19.00 \\
CRA & 1.68 & 2.00 & 0.74 & 0.00 & 3.00 \\
Private placement & 0.50 & 0.00 & 0.50 & 0.00 & 1.00 \\
Mortgage & 0.37 & 0.00 & 0.50 & 0.00 & 1.00 \\
\hline
\end{tabular}

Panel B: Comparison of means

\begin{tabular}{lccccc}
\hline & \multicolumn{2}{c}{ Pre-Referendum } & \multicolumn{2}{c}{ Post-Referendum } & \multicolumn{2}{c}{ T-test (Mean) } \\
\hline Variable & Mean & Median & Mean & Median & P-Value \\
\hline Spread (bps) & 261.34 & 215.00 & 259.96 & 210.00 & 0.95 \\
Size (million) & 232.01 & 55.29 & 139.31 & 27.75 & $0.00^{* * *}$ \\
Weighted average life (years) & 44.83 & 30.44 & 23.49 & 27.68 & $0.00^{* * *}$ \\
Credit rating & 5.26 & 3.00 & 6.36 & 5.00 & $0.00^{* * *}$ \\
CRA & 1.97 & 2.00 & 1.86 & 2.00 & $0.00^{* * *}$ \\
Private placement & 0.58 & 1.00 & 0.43 & 0.00 & $0.00^{* * *}$ \\
Mortgage & 0.41 & 0.00 & 0.41 & 0.00 & 0.70 \\
Number of Observations & 608 & & 413 & & \\
\hline
\end{tabular}

Panel C: Credit ratings assigned

\begin{tabular}{lrrrr}
\hline & \multicolumn{3}{c}{ Pre-Referendum } & \multicolumn{2}{c}{ Post-Referendum } \\
\cline { 2 - 5 } & Frequency & Percent & Frequency & Percent \\
\hline AAA & 318.00 & 37.99 & 123.00 & 25.47 \\
AA+ & 11.00 & 1.31 & 4.00 & 0.83 \\
AA & 124.00 & 14.81 & 91.00 & 18.84 \\
AA- & 22.00 & 2.63 & 7.00 & 1.45 \\
A+ & 29.00 & 3.46 & 18.00 & 3.73 \\
A & 86.00 & 10.27 & 63.00 & 13.04 \\
A- & 18.00 & 2.15 & 7.00 & 1.45 \\
BBB+ & 17.00 & 2.03 & 16.00 & 3.31 \\
BBB & 73.00 & 8.72 & 51.00 & 10.56 \\
BBB- & 16.00 & 1.91 & 9.00 & 1.86 \\
BB+ & 4.00 & 0.48 & 5.00 & 1.04 \\
BB & 61.00 & 7.29 & 38.00 & 7.87 \\
BB- & 8.00 & 0.96 & 6.00 & 1.24 \\
B+ & 4.00 & 0.48 & 3.00 & 0.62 \\
B & 8.00 & 0.96 & 7.00 & 1.45 \\
B- & 36.00 & 4.30 & 31.00 & 6.42 \\
CCC+ & 2.00 & 0.24 & & \\
CCC & & & 1.00 & 0.21 \\
CCC- & & & 3.00 & 0.62 \\
Total & 837.00 & 100.00 & 483.00 & 100.00 \\
\hline
\end{tabular}


Table 2 Brexit Referendum and securitization initial yield spreads

\begin{tabular}{|c|c|c|c|c|}
\hline \multirow{2}{*}{\multicolumn{5}{|c|}{$\begin{array}{l}\text { This table reports the results of regressions of the initial yield spread on } \mathrm{A} \\
\text { characteristics. ***, **, and * indicate statistical significance at the } 1 \%, 5 \\
\text { is } 1 \text { for the period after the referendum date (24 June } 2016 \text { ), } 0 \text { otherwise. } \\
\text { a set of dummy variables indicating from AAA to CCC-. Size is the amoun } \\
\text { captures the duration of the bond and captures the interest rate risk expo } \\
\text { the number of reported ratings by the rating agencies for a bond. It is argu } \\
\text { rating agencies are perceived to be riskier (He et al, 2016). Mortgage is } \\
\text { Private placement, which equals to } 1 \text { if the bond is sold privately (non-pul } \\
\text { for Issuer identity and quarterly time, which captures the macroeconomic }\end{array}$}} \\
\hline & & & & \\
\hline Brexit & $-188.98^{* * *}$ & $(24.26)$ & $-36.49^{* * *}$ & $(10.17)$ \\
\hline Size & -6.77 & $(4.77)$ & $-9.58 *$ & $(5.00)$ \\
\hline Weighted average life & 0.12 & (0.13) & -0.15 & $(0.14)$ \\
\hline CRA & 14.84 & $(9.83)$ & 20.75 & (13.13) \\
\hline Private placement & $-20.39 * *$ & $(8.07)$ & -5.27 & $(10.52)$ \\
\hline Mortgage & $63.15^{* * *}$ & (23.04) & $63.38^{*}$ & (32.83) \\
\hline \multicolumn{5}{|l|}{ Credit rating } \\
\hline $\mathrm{AA}^{+}$ & $41.94^{*}$ * & (18.33) & 29.96 & $(22.17)$ \\
\hline $\mathrm{AA}$ & $31.00^{* *}$ & (12.23) & $23.54^{*}$ & $(12.71)$ \\
\hline AA- & 40.12 & $(25.01)$ & 18.64 & $(23.14)$ \\
\hline $\mathrm{A}^{+}$ & 97.37 * * & $(15.44)$ & 81.80 ** * & $(16.50)$ \\
\hline A & $101.06^{* * *}$ & $(12.91)$ & $92.69^{* * *}$ & $(13.53)$ \\
\hline A- & $138.13^{* * *}$ & $(24.92)$ & $127.21^{* * *}$ & $(25.41)$ \\
\hline $\mathrm{BBB}^{+}$ & $160.60^{* * *}$ & $(22.56)$ & 146.81 * * * & $(24.06)$ \\
\hline $\mathrm{BBB}$ & $187.60^{* * *}$ & $(13.81)$ & $179.14^{* * *}$ & $(14.62)$ \\
\hline BBB- & $201.07^{* * *}$ & (22.94) & $175.28 * * *$ & $(23.73)$ \\
\hline $\mathrm{BB}^{+}$ & $233.97 * * *$ & $(33.04)$ & $235.04^{* * *}$ & $(35.85)$ \\
\hline $\mathrm{BB}$ & $360.78^{* * *}$ & $(16.49)$ & $352.73^{* * *}$ & $(17.11)$ \\
\hline BB- & $277.62^{* * *}$ & (25.62) & $253.43^{* * *}$ & $(26.52)$ \\
\hline $\mathrm{B}^{+}$ & $264.52^{* * *}$ & (34.02) & $241.95^{* * *}$ & $(38.57)$ \\
\hline B & $376.53^{* * *}$ & $(48.07)$ & $364.53^{* * *}$ & $(50.71)$ \\
\hline B- & $510.93^{* * *}$ & $(20.86)$ & $498.43^{* * *}$ & $(21.65)$ \\
\hline $\mathrm{CCC}^{+}$ & $359.90^{* * *}$ & $(27.84)$ & 369.22 ** * & (32.33) \\
\hline $\mathrm{CCC}$ & $354.00^{* * *}$ & (15.69) & $339.49^{* * *}$ & $(16.42)$ \\
\hline CCC- & $269.41^{* * *}$ & $(20.32)$ & $218.72^{* * *}$ & $(22.50)$ \\
\hline Issuer identity & Yes & & Yes & \\
\hline Time (Quarterly) & Yes & & No & \\
\hline \# of observations & 1,021 & & 1,021 & \\
\hline
\end{tabular}


This table reports the results of regressions of the initial yield spread of prime and non-prime ABS/MBS bonds and macro-economic characteristics. *** ${ }^{* *}$, and * indicate statistical significance at the $1 \%, 5 \%$, and $10 \%$ levels, respectively. Brexit is 1 for the period after the referendum date (24 June 2016$)$, 0 otherwise. Credit Rating a of bond is captured by a set of dummy variables indicating from AAA to CCC-. Size is the amount of the bond. Weighted Average Life captures the duration of the bond and captures the interest rate risk exposure. Credit Rating Agencies (CRA) is the number of reported ratings by the rating agencies for a bond. It is argued that bonds rated by less than three rating agencies are perceived to be riskier (He et al, 2016). Mortgage is 1 if the bond is an MBS, 0 otherwise. Private placement, which equals to 1 if the bond is sold privately (non-public offering), 0 otherwise. We control for Issuer identity and quarterly time, which captures the macroeconomic environment.

\begin{tabular}{|c|c|c|c|c|c|c|c|c|}
\hline \multirow[b]{3}{*}{ Brexit } & \multicolumn{4}{|c|}{ Prime } & \multicolumn{4}{|c|}{ Non-prime } \\
\hline & \multicolumn{2}{|c|}{ (1) } & \multicolumn{2}{|l|}{ (2) } & \multicolumn{2}{|c|}{ (3) } & \multicolumn{2}{|c|}{ (4) } \\
\hline & $-180.71^{* * *}$ & $(28.90)$ & $-62.82^{* * *}$ & $(10.81)$ & $-153.43^{* * *}$ & $(29.56)$ & $-25.28 * *$ & $(12.45)$ \\
\hline Size & -1.75 & $(6.37)$ & -4.00 & $(5.90)$ & $-12.72^{*}$ & $(7.14)$ & $-21.64^{* *}$ & (8.33) \\
\hline Weighted average life & -0.08 & $(0.13)$ & -0.18 & $(0.16)$ & 0.04 & $(0.16)$ & -0.17 & $(0.20)$ \\
\hline CRA & 0.60 & $(8.65)$ & -3.53 & $(15.5)$ & 14.66 & (17.33) & $45.81^{\text {* * }}$ & (21.63) \\
\hline Private placement & $-24.52^{* * *}$ & (24.24) & $72.28^{*}$ & (11.24) & -9.40 & $(9.30)$ & 36.02 & (12.86) \\
\hline Mortgage & $71.21^{* * *}$ & $(8.93)$ & -16.96 & (38.49) & $62.65^{* *}$ & (28.43) & 6.05 & (29.79) \\
\hline \multicolumn{9}{|l|}{ Credit rating } \\
\hline AA & & & & & -27.53 & $(17.71)$ & -14.90 & $(24.59)$ \\
\hline AA- & & & & & -11.65 & (33.76) & -6.66 & (34.87) \\
\hline $\mathrm{A}^{+}$ & & & & & $52.95^{* * *}$ & $(16.46)$ & $58.81^{\text {* * }}$ & (23.78) \\
\hline $\mathrm{A}$ & & & & & 31.31 * & (18.18) & 39.87 & $(24.97)$ \\
\hline A- & & & & & $84.53^{* * *}$ & (27.18) & $108.51^{* * *}$ & $(31.70)$ \\
\hline $\mathrm{BBB}^{+}$ & & & & & $108.11^{* * *}$ & $(19.85)$ & $115.70^{* * *}$ & $(28.00)$ \\
\hline $\mathrm{BBB}$ & & & & & $116.81^{* * *}$ & (17.68) & $124.00^{* * *}$ & $(24.89)$ \\
\hline BBB- & & & & & $136.52^{* * *}$ & $(20.31)$ & $126.73^{* * *}$ & (26.58) \\
\hline $\mathrm{BB}^{+}$ & & & & & 171.20 ** * & (33.48) & $196.61^{* * *}$ & (38.99) \\
\hline $\mathrm{BB}$ & & & & & $289.57^{* * *}$ & (19.24) & $298.19^{* * *}$ & $(25.90)$ \\
\hline BB- & & & & & $206.39^{* * *}$ & (22.36) & $201.09^{* * *}$ & (27.43) \\
\hline $\mathrm{B}^{+}$ & & & & & $209.25^{* * *}$ & $(31.05)$ & $206.53^{* * *}$ & (38.67) \\
\hline B & & & & & $307.33^{* * *}$ & $(45.94)$ & $311.57^{* * *}$ & $(49.91)$ \\
\hline B- & & & & & $433.44^{* \text { * * }}$ & $(22.06)$ & $430.54^{* * *}$ & (28.56) \\
\hline $\mathrm{CCC}^{+}$ & & & & & $281.54^{* * *}$ & $(23.82)$ & $332.95^{* * *}$ & (30.62) \\
\hline $\mathrm{CCC}$ & & & & & $297.28^{* * *}$ & (12.59) & $296.23^{* * *}$ & (17.67) \\
\hline CCC- & & & & & $234.23^{* * *}$ & (22.11) & $207.29^{* * *}$ & (28.75) \\
\hline Issuer identity & Yes & & Yes & & Yes & & Yes & \\
\hline Time (Quarters) & Yes & & No & & Yes & & No & \\
\hline \# of observations & 342 & & 342 & & 679 & & 679 & \\
\hline
\end{tabular}




\section{Table 4. MBS versus ABS}

This table reports the results of regressions of the initial yield spread of ABS/MBS bonds and macro-economic characteristics. ${ }^{* * *}$, * , and ${ }^{*}$ indicate statistical significance at the $1 \%, 5 \%$, and $10 \%$ levels, respectively. Brexit is 1 for the period after the referendum date (24 June 2016$)$, 0 otherwise. Credit Rating a of bond is captured by a set of dummy variables indicating from AAA to CCC-. Size is the amount of the bond. Weighted Average Life captures the duration of the bond and captures the interest rate risk exposure. Credit Rating Agencies (CRA) is the number of reported ratings by the rating agencies for a bond. It is argued that bonds rated by less than three rating agencies are perceived to be riskier (He et al, 2016). Mortgage is 1 if the bond is an MBS, 0 otherwise. Private placement, which equals to 1 if the bond is sold privately (non-public offering), 0 otherwise. We control for Issuer

identity and quarterly time, which captures the macroeconomic environment.

\begin{tabular}{|c|c|c|c|c|c|c|c|c|}
\hline \multirow[b]{3}{*}{ Brexit } & \multicolumn{4}{|c|}{ MBS } & \multicolumn{4}{|c|}{$\mathrm{ABS}$} \\
\hline & \multicolumn{2}{|l|}{ (1) } & \multicolumn{2}{|l|}{ (2) } & \multicolumn{2}{|l|}{ (3) } & \multicolumn{2}{|l|}{ (4) } \\
\hline & $-91.95^{*}$ & $(54.29)$ & -14.97 & $(21.42)$ & $-165.41^{* * *}$ & (33.58) & $-36.49 * * *$ & $(11.86)$ \\
\hline Size & $-12.16^{*}$ & $(6.91)$ & $-16.05^{* *}$ & $(7.12)$ & -7.05 & $(5.40)$ & -6.399 & $(5.38)$ \\
\hline $\begin{array}{l}\text { Weighted average } \\
\text { life }\end{array}$ & $0.94^{* * *}$ & $(0.35)$ & 0.01 & $(0.29)$ & -0.02 & $(0.17)$ & -0.1867 & $(0.15)$ \\
\hline CRA & -7.32 & (13.36) & -3.81 & $(15.50)$ & -12.45 & $(14.79)$ & 16.2821 & $(22.65)$ \\
\hline Private placement & $-54.01 * *$ & (21.16) & $-29.62^{*}$ & $(15.72)$ & 0.73 & $(6.36)$ & 10.131 & (12.98) \\
\hline Mortgage & $102.91^{* * *}$ & (38.83) & 26.95 & $(25.91)$ & $-62.80 * * *$ & $(15.05)$ & $-61.8091 * * *$ & $(17.34)$ \\
\hline \multicolumn{9}{|l|}{ Credit rating } \\
\hline $\mathrm{AA}^{+}$ & -2.02 & $(26.90)$ & -23.94 & $(26.43)$ & 31.18 & $(23.17)$ & 23.389 & $(18.01)$ \\
\hline $\mathrm{AA}$ & 4.67 & (21.18) & -15.11 & $(21.96)$ & $52.91^{* * *}$ & $(8.82)$ & $55.4478^{* * *}$ & $(9.17)$ \\
\hline AA- & 11.96 & $(30.75)$ & -16.50 & $(29.23)$ & $56.89^{*}$ & (33.84) & 50.7797 & $(32.07)$ \\
\hline $\mathrm{A}^{+}$ & $59.29^{* * *}$ & $(22.46)$ & $43.98^{*}$ & $(23.72)$ & 27.30 & (16.58) & 16.4277 & (15.68) \\
\hline $\mathrm{A}$ & $70.04^{* * *}$ & (23.84) & $49.70^{* *}$ & $(23.50)$ & $123.97^{* * *}$ & (11.27) & $126.2408^{* * *}$ & (11.62) \\
\hline A- & $94.95^{* * *}$ & $(26.01)$ & $84.69^{* * *}$ & $(29.85)$ & $159.40^{* * *}$ & $(43.10)$ & $167.0834^{* * *}$ & $(53.24)$ \\
\hline $\mathrm{BBB}^{+}$ & $111.69^{* * *}$ & $(28.51)$ & $91.62^{* * *}$ & $(28.95)$ & $290.18^{* * *}$ & (31.98) & $360.9286^{* * *}$ & $(48.81)$ \\
\hline $\mathrm{BBB}$ & $118.02^{* * *}$ & $(27.70)$ & $99.25^{* * *}$ & (28.67) & $218.48^{* * *}$ & $(12.21)$ & $221.9285^{* * *}$ & $(12.71)$ \\
\hline BBB- & $181.66^{* * *}$ & $(39.71)$ & $142.78^{* * *}$ & (36.54) & $203.78^{* * *}$ & $(19.32)$ & $182.8636^{* * *}$ & $(21.80)$ \\
\hline $\mathrm{BB}^{+}$ & $179.90^{* * *}$ & $(35.22)$ & $163.42^{* * *}$ & $(36.75)$ & $416.54^{* * *}$ & $(31.44)$ & $487.1661^{* * *}$ & $(48.46)$ \\
\hline $\mathrm{BB}$ & $204.56^{* * *}$ & $(35.24)$ & $198.43^{* * *}$ & $(37.29)$ & $400.92^{* * *}$ & $(14.46)$ & $403.8269^{* * *}$ & $(14.77)$ \\
\hline BB- & $232.93^{* * *}$ & $(40.63)$ & $189.73^{* * *}$ & (35.16) & $344.72^{* * *}$ & $(33.52)$ & $327.2048^{* * *}$ & (30.96) \\
\hline $\mathrm{B}^{+}$ & $185.79^{* * *}$ & (29.98) & $139.51^{* * *}$ & (30.93) & $429.66^{* * *}$ & $(71.25)$ & $449.9857^{* * *}$ & $(99.77)$ \\
\hline $\mathrm{B}$ & $202.81^{* * *}$ & $(47.11)$ & $186.36^{* * *}$ & $(49.84)$ & $505.94^{* * *}$ & $(41.10)$ & $512.0733^{* * *}$ & $(51.51)$ \\
\hline B- & $282.68^{* * *}$ & $(32.00)$ & $239.84^{* * *}$ & $(35.11)$ & $544.56^{* * *}$ & (19.18) & $544.4559 * * *$ & (19.49) \\
\hline $\mathrm{CCC}^{+}$ & $301.12^{* * *}$ & $(36.41)$ & $308.92^{* * *}$ & $(40.78)$ & & & & \\
\hline $\mathrm{CCC}$ & $310.02^{* * *}$ & (26.38) & $286.78^{* * *}$ & (25.39) & & & & \\
\hline CCC- & $217.41^{* * *}$ & (26.73) & $190.88^{* * *}$ & (30.84) & & & & \\
\hline Issuer identity & Yes & & Yes & & Yes & & Yes & \\
\hline Time (Quarterly) & Yes & & No & & Yes & & No & \\
\hline \# of observations & 422 & & 422 & & 599 & & 599 & \\
\hline
\end{tabular}


Table 5 Propensity score matching results

\begin{tabular}{|c|c|c|c|c|c|}
\hline \multicolumn{6}{|c|}{$\begin{array}{l}\text { This table reports results for the propensity score matching estimates of the average treatment effect (ATT). The treatment } \\
\text { group is ABS/MBS issued before the BR. Treatment group is matched with the control group using the propensity score } \\
\text { which is a function of all observable characteristic described above (excluding time-dummy variables). Robust standard errors } \\
\text { are bootstrapped. }{ }^{* * *},{ }^{* *} \text { and * } \text { represents significance levels at } 1 \%, 5 \% \text { and } 10 \% \text {, respectively. }\end{array}$} \\
\hline \# of controls matched & All & Prime & Non-prime & $\mathrm{ABS}$ & MBS \\
\hline One & $-50.38 * * *$ & $-57.55^{* * *}$ & $-42.79 * * *$ & $-58.59 * * *$ & 8.11 \\
\hline Two & $-45.01 * * *$ & $-49.97 * * *$ & $-34.90 * * *$ & $-59.31^{* * *}$ & 17.36 \\
\hline Four & $-34.90 * * *$ & $-52.35^{* * *}$ & $-36.32 * * *$ & $-50.24 * * *$ & 10.80 \\
\hline Matched observations & 1,017 & 340 & 677 & 599 & 418 \\
\hline
\end{tabular}

